\title{
Identification of CDKN2A variants in breast cancer patients in Pakistan
}

\author{
Ranjha Khan ${ }^{1}$, Ayesha Aftab ${ }^{2}$, Sobia Tabassum ${ }^{2}$, Hafiz Muhammad Jafar Hussain ${ }^{1}$, \\ Abdul Hameed ${ }^{3}$, Humera Mahmood ${ }^{4}$, Faiza Munir ${ }^{2}$ and Ihtisham Bukhari ${ }^{5 *}$ \\ ${ }^{1}$ The CAS Key Laboratory of Innate Immunity and Chronic Diseases, School of Life Sciences, University of \\ Science and Technology of China, Huangshan Road, Hefei, Anhui 230027, China \\ ${ }^{2}$ Department of Biological Sciences, International Islamic University, Sector H10, \\ Islamabad 44000, Pakistan \\ ${ }^{3}$ Institute of Biomedical and Genetic Engineering (IBGE), Kashmir Highway, \\ 1, Service Road South, G9/1, Islamabad 44000, Pakistan \\ ${ }^{4}$ Department of Oncology, Nuclear Medicine Oncology \& Radiotherapy \\ Institute (NORI) Hospital, Hanna Road, G8/3, \\ Islamabad 44000, Pakistan \\ ${ }^{5}$ Translational Research Institute, Henan Provincial People's Hospital, \\ School of Medicine, Henan University, Huanghe Road, \\ Zhengzhou, Henan 450053, China
}

(Received 30 October 2018, accepted 25 February 2019; J-STAGE Advance published date: 21 June 2019)

The role of cyclin-dependent kinase inhibitor $2 \mathrm{~A}$ gene $(C D K N 2 A)$ variants in breast cancer is not well understood, here we investigated their possible effects on breast cancer in Pakistani women attending the NORI Hospital, Islamabad. Direct DNA sequencing of CDKN2A identified an already known polymorphism in the $3^{\prime}$ UTR, c.*29G >C (rs11515), in $5.88 \%$ patients and two novel variants. One, a deep intronic substitution (c.458-554T $>$ G) in $1.96 \%$ patients, is also detected as a compound heterozygous form along with c. ${ }^{*} 29 \mathrm{G}>\mathrm{C}$ in $1.96 \%$ patients (c. [458$554 \mathrm{~T}>\mathrm{G} ; * 29 \mathrm{G}>\mathrm{C}])$. The other is a novel deletion (c.458-82delG) occurring as a compound variant with two other identified variants c.[458-554T> G; 458-82delG; $* 29 \mathrm{G}>\mathrm{C}]$ in $1.96 \%$ patients. In silico pathogenicity prediction analyses did not predict pathogenic effects on breast cancer for these individual variants. We conclude that variations in $C D K N 2 A$ are not the major genetic cause of breast cancer in the enrolled Pakistani patients.

Key words: breast cancer, $C D K N 2 A, p 16 I N K 4 A$, polymorphisms, mutations

\section{INTRODUCTION}

Breast cancer is one of the world's leading causes of female mortality. Among Asian countries, Pakistan has the highest rate of breast cancer, possibly due to unawareness about breast health, low socioeconomic condition and genetic background (Menhas and Umer, 2015). Several genetic risk factors and causes of breast cancer have been identified, one of which is the cyclin-dependent kinase inhibitor (CDKN2A/p16INK4A) gene. CDKN2A (OMIM no. 600160) is a tumour suppressor gene located on the short arm of chromosome 9 (9q21) (Rayess et al., 2012), and encodes p16 protein, which plays a key role in cell division during early G1 phase by inhibiting the pro-

Edited by Hideki Innan

* Corresponding author. E-mail: bukhari5408@gmail.com DOI: http://doi.org/10.1266/ggs.18-00053 gression of the cell cycle from G1 to S phase (Shan et al., 2013). CDKN2A is a principal controller during cell division and most tumours, including breast cancer, show dysregulation in the p16 pathway (Shan et al., 2013).

Mutations in or functional inactivation of CDKN2A are known to be involved in numerous types of human cancers, such as leukaemia, lung cancer, oesophageal cancer, glioma, breast cancer and melanoma (Hinshelwood et al., 2009; McKenzie et al., 2010; Puig et al., 2016). It is primarily a melanoma-associated gene and mutations have been reported in 24\% of melanoma-prone Latin America families (Puig et al., 2016). Similarly, 14\% of Spanish melanoma patients also harbour CDKN2A variants (Puig et al., 2016). However, $C D K N 2 A$ has shown no clear association with breast cancer in several other populations or ethnic groups (Berns et al., 1995; Quesnel et al., 1995; Horcasitas et al., 2017; Aftab et al., 2019). To help resolve the ambiguity regarding pathogenic effects of CDKN2A 
on breast cancer, we recruited breast cancer patients from the Nuclear Medicine Oncology \& Radiotherapy Institute (NORI) Hospital in Islamabad, Pakistan. Through DNA sequencing, we identified mutations/polymorphisms in $C D K N 2 A$ and predicted the pathogenicity of each identified $C D K N 2 A$ mutation/polymorphism in current breast cancer patients using various online bioinformatics tools.

\section{MATERIALS AND METHODS}

Subjects Fifty-one women diagnosed with breast cancer were recruited from the NORI Hospital. The ethical committee and institutional review board of the International Islamic University, Islamabad, Pakistan approved all sampling and experimental procedures, which were performed by strictly following the ethical standards of the 1964 Declaration of Helsinki and its latest amendments, or comparable ethical standards. Informed written consent was obtained from all participants.

DNA extraction and genotyping Venous blood samples $(5-10 \mathrm{ml})$ were collected from each patient into ethylenediaminetetraacetic acid tubes. DNA was extracted by the phenol-chloroform method and CDKN2A was amplified using specially designed primers (Supplementary Table S1) with the Thermo Hybaid PXE 0.2 PCR system, in a $30-\mu \mathrm{l}$ reaction containing $3.0 \mu \mathrm{l}$ of $10 \%$ PCR

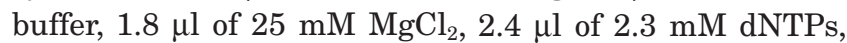
$0.6 \mu \mathrm{l}$ of PrimeSTAR HS DNA polymerase and $1.5 \mu \mathrm{l}$ of $5 \%$ dimethyl sulphoxide. PCR products were denatured at $95{ }^{\circ} \mathrm{C}$ for $5 \mathrm{~min}$ and analysed via single-strand conformation polymorphism (SSCP) on an $8 \%$ polyacrylamide gel run at $30 \mathrm{~W}$ for $4 \mathrm{~h}$. The gel was stained with ethidium bromide and visualized with a UV transilluminator. Products with an altered electrophoretic mobility characteristic of single-stranded DNA were sequenced using an ABI 3130 Genetic Analyzer (Applied Biosystems PRISM 310, Foster City, CA, USA). The files generated were further inspected by Sequencing Analysis 5.2 software (Applied Biosystems).

In silico analyses To predict the impact of identified variants on splicing, we used different online tools. Human Splicing Finder (http://www.umd.be/HSF3/), SROOGLE (http://sroogle.tau.ac.il/) and NetGene2 (http://www.cbs. $\mathrm{dtu} . \mathrm{dk} /$ services/NetGene2/) were used to evaluate the effect of intronic variants, while VarioWatch (http:// grch38.genepipe.ncgm.sinica.edu.tw/variowatch/main.do), UTRScan (http://itbtools.ba.itb.cnr.it/utrscan) and the PolymiRTS database 3.0 were used for analysis of $3^{\prime}$ UTR single-nucleotide polymorphisms (SNPs).

\section{RESULTS}

Identification of variants PCR-SSCP analysis of CDKN2A amplicons revealed band alterations on SSCP gels in six of the 51 samples (Supplementary Fig. S1). For further clarification, we performed DNA sequencing of these samples, which identified one already known polymorphism and three novel variants including an intronic substitution and two compound variants (Table 1). The known 3' UTR variant (c. ${ }^{* 29 G>C)}$ was identified in three patients $(5.88 \%)$, of whom one had the heterozygous form and two the homozygous form of the mutation (Fig. 1A). A deep intronic heterozygous substitution (c.458-554T > G) in intron 2 was detected in one patient $(1.96 \%)$ (Fig. 1B), while another was found to have a deletion mutation (c.458-82delG) in intron 2 (Fig. 1C); this patient also carried two other mutations, c. $* 29 \mathrm{G}>\mathrm{C}$ and c.458-554T $>$ G, making her an exceptional case with three mutations, which is an extremely rare form of compound mutations. Another patient carried two variants, c. $458-554 \mathrm{~T}>\mathrm{G}$ and c. ${ }^{*} 29 \mathrm{G}>\mathrm{C}$ (Table 1$)$.

Predicting the functional impact of identified variants using in silico tools Human Splicing Finder (HSF) analysis predicted that c.458-554T $>\mathrm{G}$ causes a new acceptor site, which would affect splicing. Variant c.458-82delG also showed a high positive variation percentage, predicted to create a new acceptor site, although HSF anticipated that this new site would have no effect on splicing. SROOGLE and NetGene2 analyses predicted little or no difference between wild-type and mutant scores, with no effect on splicing. Thus, overall, HSF analyses did not predict any substantial role for the newly identified variants in splicing patterns (Table 2).

VarioWatch predicted that the 3' UTR SNP (rs11515) has no functional impact on splicing. In the 'genome

Table 1. CDKN2A variants identified in breast cancer patients

\begin{tabular}{|c|c|c|c|c|c|}
\hline Variant & Type & Location & $\begin{array}{c}\text { Nucleotide } \\
\text { change }\end{array}$ & $\begin{array}{c}\text { Frequency } \\
(\%)\end{array}$ & Reference \\
\hline c. $458-554 \mathrm{~T}>\mathrm{G}$ & Substitution & Intron 2 & $\mathrm{~T}>\mathrm{G}$ & 1.96 & This study \\
\hline c. $* 29 \mathrm{G}>\mathrm{C}$ & SNP & 3' UTR & $\mathrm{G}>\mathrm{C}$ & 5.88 & $\begin{array}{l}\text { Kitts and Sherry, } \\
2011\end{array}$ \\
\hline c. $[458-554 \mathrm{~T}>\mathrm{G} ; * 29 \mathrm{G}>\mathrm{C}]$ & Compound Mutation & Intron $2 \& 3^{\prime}$ UTR & - & 1.96 & This study \\
\hline c. $[458-554 \mathrm{~T}>\mathrm{G} ; 458-82 \mathrm{del} ; * 29 \mathrm{G}>\mathrm{C}]$ & Compound Mutation & Intron $2 \& 3^{\prime}$ UTR & - & 1.96 & This study \\
\hline
\end{tabular}


A.

Wild-type

G A A A C C T C G G G A A A

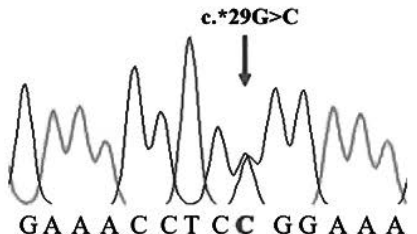

Heterozygous
B.

Wild-type

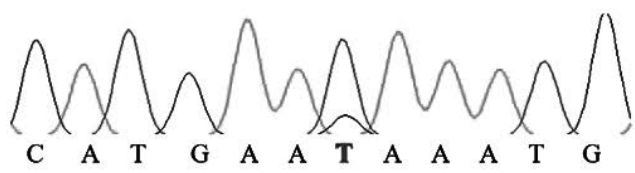

Heterozygous

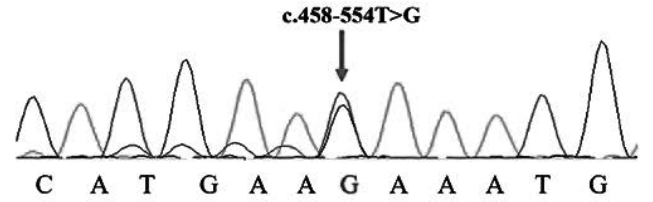

C.

Homozygous

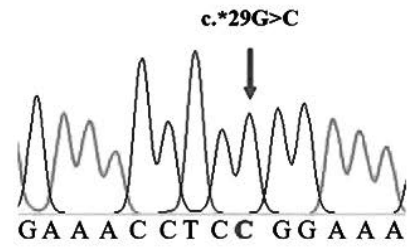

Wild-type

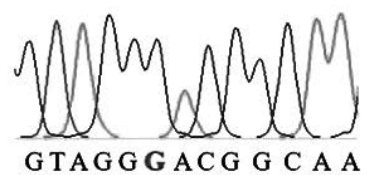

Homozygous

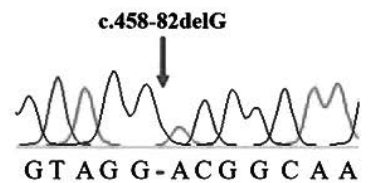

Fig. 1. Chromatograms representing the identified CDKN2A variants. (A) Wild-type sequence given with heterozygous and homozygous SNP (c. ${ }^{*} 29 \mathrm{G}>\mathrm{C}$ ) rs11515 found in the $3^{\prime}$ UTR. (B) A heterozygous deep intronic substitution (c.458-554T $>$ G) in intron 2. (C) A homozygous deep intronic deletion (c.458-82delG) in intron 2.

Table 2. In silico analysis of intronic variants for predicting impact on splicing

\begin{tabular}{|c|c|c|c|c|c|c|c|c|}
\hline \multirow{3}{*}{ Variants } & \multicolumn{4}{|c|}{$\mathrm{HSF}^{\mathrm{a}}$} & \multirow{2}{*}{$\begin{array}{l}\text { SROOGLE }^{\mathrm{b}} \\
\text { Range (1-100) }\end{array}$} & \multirow{2}{*}{\multicolumn{2}{|c|}{$\begin{array}{l}\text { NetGene } 2^{\mathrm{c}} \\
\text { Range (0-1) }\end{array}$}} & \multirow{3}{*}{$\begin{array}{c}\text { Prediction of } \\
\text { possible functional } \\
\text { impact** }\end{array}$} \\
\hline & \multicolumn{4}{|c|}{ HSF metric score range (1-100) } & & & & \\
\hline & $\begin{array}{l}\text { Wild- } \\
\text { type }\end{array}$ & Mutant & Variation $(\%)$ & Interpretation $^{\mathrm{a}}$ & $\begin{array}{l}\text { Wild- } \\
\text { type }\end{array}$ & WT & Mutant & \\
\hline \multirow[t]{2}{*}{ c. $458-554 \mathrm{~T}>\mathrm{G}$} & 39.78 & 68.72 & +72.75 & New A.S. ${ }^{a}$ & $\begin{array}{l}\text { No difference } \\
\text { in scores }\end{array}$ & $\begin{array}{l}\text { No splice site } \\
\text { role detected }\end{array}$ & $\begin{array}{l}\text { No splice site } \\
\text { role detected }\end{array}$ & $\begin{array}{l}\text { No effect on } \\
\text { splicing }\end{array}$ \\
\hline & & & & $\begin{array}{l}\text { Probably affects } \\
\text { splicing }\end{array}$ & & & & \\
\hline c. $458-82 \mathrm{delG}$ & 65.13 & 41.27 & +57.81 & $\begin{array}{l}\text { Probably no } \\
\text { effect on splicing }\end{array}$ & $\begin{array}{l}\text { No difference } \\
\text { in scores }\end{array}$ & 0.44 D.S. ${ }^{c}$ & 0.53 D.S. & $\begin{array}{l}\text { No effect on } \\
\text { splicing }\end{array}$ \\
\hline
\end{tabular}

${ }^{a}$ HSF = Human Splicing finder; variation $\%>+10 \%$ predicts that the mutation creates a new splice site $($ A.S. $=$ acceptor site). Interpretation done by HSF, http://www.umd.be/HSF3/index.html.

${ }^{\mathrm{b}}$ In SROOGLE, the effect on splicing is predicted through the difference between wild-type and mutant scores; scores close to 1 are signalled as strong splice sites, http://sroogle.tau.ac.il/.

${ }^{\mathrm{c}}$ NetGene2 = neural network prediction server; predicts the acceptor site (A.S.) and donor site (D.S.); scores close to 1 are signalled as strong splice sites, http://www.cbs.dtu.dk/services/NetGene2/output.php.

** Prediction of overall possible impact.

view' results generated by this tool, a graphic representation of all chromosomes is given with highlighted colours for the position and risk level of a selected SNP (Fig. 2 ); the black colour associated with rs11515 indicates that this SNP has no functional impact (Cheng et al.,
2012). The UTRScan server predicted that rs11515 has no damaging or other impact on the putative microRNA target site. Further analysis using the PolymiRTS database predicted that rs11515 has a changed motif pattern for miRNA binding. The high negative context + score 


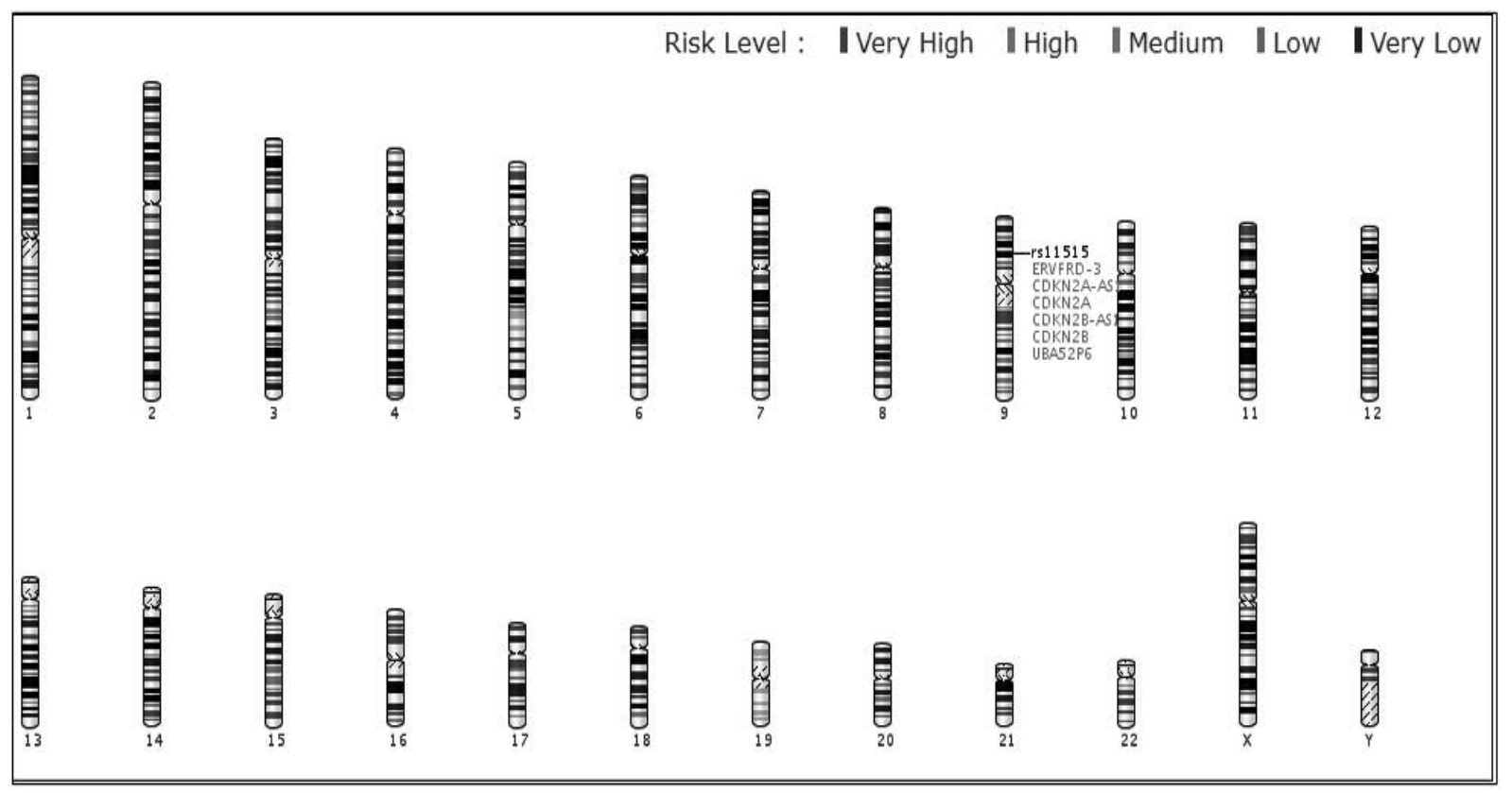

Fig. 2. Genomic location and breast cancer risk level of rs11515. The in silico SNP annotation tool VarioWatch located rs11515 on chromosome 9. The colour code is supplied by the tool; the black colour for the SNP indicates no functional risk (Cheng et al., 2012).

Table 3. PolymiRTS database 3.0 prediction of the functional impact of the 3' UTR SNP rs11515

\begin{tabular}{lccccc}
\hline \hline SNP ID & Variation & miRNA ID & miRNA site & Predicted impact & Context + score** \\
\hline rs11515 & c.*29G $>$ C & hsa-miR-4740-3p & aacCTCGGGAaac & Creates a new miRNA site & -0.24 \\
\hline ** Context + score evaluates the influence of SNP on miRNA-mRNA interaction; the negative context + score \\
value difference means that a target site may have been disrupted or a new one created (http://compbio.uthsc. \\
edu/miRSNP/home.php).
\end{tabular}

indicated that a new target site has been created (Table 3). We were unable to predict the pathogenicity scores of the variants existing as double or triple compound forms because none of the tools used could analyse such complex variants.

\section{DISCUSSION}

Alternative splicing of $C D K N 2 A$ generates two distinct transcripts, i.e., $p 16 I N K 4 A$ and $p 14 A R F$. Both transcripts have been extensively studied in various cancers. Although the role of transcripts cannot be neglected, $p 14 A R F$ did not show any association with cancers (Rocco and Sidransky, 2001). In the current research, we focused on the identification and in silico prediction of $C D K N 2 A$ variants in breast cancer patients recruited from the NORI Hospital in Islamabad, Pakistan.

The association of $C D K N 2 A$ with different cancers has been studied extensively and $C D K N 2 A$ is reported to be a melanoma-prone tumour suppressor (Agarwal et al., 2012; Helgadottir et al., 2016) that is mutated in different cancers (Oliveira et al., 2005). Various studies have investigated the association of $C D K N 2 A$ variants with breast cancer. Some showed reasonable association (Silva et al., 2003; Phyllodes Tumour Consortium, 2008; Jovanovic et al., 2010; Spitzwieser et al., 2017), but most have shown little or no clear association with breast cancer (Berns et al., 1995; Musgrove et al., 1995; Nagore et al., 2009; Aftab et al., 2019). Previously, the nonsense mutation p.R80X was found to be associated with ductal and metaplastic breast carcinoma (Guerini-Rocco et al., 2016; Nik-Zainal et al., 2016). Several studies have shown a role for this gene in breast cancer development by deleting $C D K N 2 A$ altogether or suppressing its expression in breast cancer cell lines (Brenner and Aldaz, 1995; Tan et al., 2014; Dwyer and Clark, 2015). Surprisingly, some studies revealed that breast cancer cell lines have more mutations than the primary and germline breast cancer samples (Xu et al., 1994; Sonkin et al., 2013; Morris and Chan, 2015; de Oliveira et al., 2016).

Nowadays, great effort is being made to investigate the effect of intronic variants on gene splicing and expression, which ultimately lead to apparent phenotypic changes in human (Khurana et al., 2016). Previously, the two intronic mutations c. $150+2 \mathrm{~T}>\mathrm{C}$ and c.151-1G $>\mathrm{C}$ showed a significant effect on breast cancer (Prowse et al., 2003; 
Hollestelle et al., 2010). Not all intronic or exonic variants are pathogenic: in a recent study the two deep intronic variants c.458-82delG and c.458-554T $>\mathrm{G}$ showed no significant effect on splicing, and thus did not affect gene or protein expression. Furthermore, c.458-82delG was also predicted to be non-pathogenic as it does not cause any frameshift or change in protein conformation. However, we found that two patients had compound forms of mutations which are believed to be pathogenic. Liu et al. (2015) concluded in their work that multiple mutations in a single gene can lead to a higher severity of the disease than single mutations. We believe that the occurrence of a solo mutation in patients may not be pathogenic, but its occurrence as a compound with other mutation(s) may produce a significant effect on disease pathology. Compound mutations could cause severe disruption of splicing or translation, and ultimately lead to a severe phenotype (Kim et al., 2016). Likewise, Fu et al. (2018) have reported that a compound heterozygous mutation in the USH2A gene was pathogenic.

The $3^{\prime}$ UTR has a crucial role in gene regulation and expression (Kitts and Sherry, 2011). rs11515 has a higher minor allelic frequency, 0.16, in Africans (Kitts and Sherry, 2011). Several studies have shown a potential role for rs11515 in tumour development and a functional relationship between $\mathrm{rs} 11515$ and a microRNA binding site (Chen et al., 2008; Landi et al., 2008; Robertson et al., 2010; Turgut et al., 2017). It has been reported that rs11515 is commonly associated with aggressive breast cancer in patients from New Zealand (Royds et al., 2016) although, in contradiction, a recent meta-analysis did not show an association with breast cancer in an Asian population (Dong et al., 2017). Furthermore, the rs11515 region has a recognition motif for miR-601 (Chen et al., 2008; Landi et al., 2008), while, according to our analysis, the PolymiRTS database shows that it has such a motif for hsa-miR-4740-3p (MIMAT0019870) (Table 3). The interaction between miRNA and rs11515 thus needs further investigation, and large population-based studies are needed to assess the association of rs11515 and other polymorphisms in the Pakistani breast cancer population.

In summary, the variants identified in this research can assist breast cancer prognosis in the Pakistani population. The current findings are consistent with previous findings, i.e., $C D K N 2 A$ is not frequently mutated in breast cancer patients (Horcasitas et al., 2017; Aftab et al., 2019), but here we present two novel variants (c.458$554 \mathrm{~T}>\mathrm{G}$ and c.458-82delG) in CDKN2A. The crosssectional study design and low sample size are major limitations of the study. Further screening of additional breast cancer samples will clarify the pathogenic role of the identified variants.

\section{CONFLICT OF INTEREST}

All authors declare that they have no conflict of interest.

\section{REFERENCES}

Aftab, A., Shahzad, S., Hussain, H. M. J., Khan, R., Irum, S., and Tabassum, S. (2019) CDKN2A / P16INK4A variants association with breast cancer and their in-silico analysis. Breast Cancer 26, 11-28.

Agarwal, P., Kabir, F. M. L., DeInnocentes, P., and Bird, R. C. (2012) Tumor Suppressor Gene p16/INK4A/CDKN2A and Its Role in Cell Cycle Exit, Differentiation, and Determination of Cell Fate. In: Tumor Suppressor Genes. (ed.: Cheng, Y.), pp. 1-34. InTech, Rijeka, Croatia.

Berns, E. M., Klijn, J. G., Smid, M., van Staveren, I. L., Gruis, N. A., and Foekens, J. A. (1995) Infrequent CDKN2 (MTS1) p16) gene alterations in human primary breast cancer. Br. J. Cancer 72, 964-967.

Brenner, A. J., and Aldaz, C. M. (1995) Chromosome 9p allelic loss and p16/CDKN2 in breast cancer and evidence of $p 16$ inactivation in immortal breast epithelial cells. Cancer Res. 55, 2892-2895.

Chen, K., Song, F., Calin. G. A., Wei, Q., Hao, X., and Zhang, W. (2008) Polymorphisms in microRNA targets: a gold mine for molecular epidemiology. Carcinogenesis 29, 1306-1311.

Cheng, Y. C., Hsiao, F. C., Yeh, E. C., Lin, W. J., Tang, C. Y. L., Tseng, H. C., Wu, H. T., Liu, C. K., Chen, C. C., Chen, Y. T., et al. (2012) VarioWatch: providing large-scale and comprehensive annotations on human genomic variants in the next generation sequencing era. Nucleic Acids Res. 40, W76-W81.

de Oliveira, S. F. V., Ganzinelli, M., Chilà, R., Serino, L., Maciel, M. E., de Andrade Urban, C., de Lima, R. S., Cavalli, I. J., Generali, D., Broggini, M., et al. (2016) Characterization of MTAP gene expression in breast cancer patients and cell lines. PLoS One 11, e0145647.

Dong, Y., Wang, X., Yang, Y. W., and Liu, Y. J. (2017) The effects of CDKN2A rs3731249, rs11515, and rs3088440 polymorphisms on cancer risk. Cell. Mol. Biol. 63, 40-44.

Dwyer, J. B., and Clark, B. Z. (2015) Low-grade fibromatosislike spindle cell carcinoma of the breast. Arch. Pathol. Lab. Med. 139, 552-557.

Fu, Y. C., Chen, N., Qiu, Z. L., Liu, L., and Shen, J. (2018) Compound pathogenic mutation in the USH2A gene in Chinese RP families detected by whole-exome sequencing. Mol. Med. Rep. 18, 5016-5022.

Guerini-Rocco, E., Piscuoglio, S., Ng, C. K. Y., Geyer, F. C., De Filippo, M. R., Eberle, C. A., Akram, M., Fusco, N., Ichihara, S., Sakr, R. A., et al. (2016) Microglandular adenosis associated with triple-negative breast cancer is a neoplastic lesion of triple-negative phenotype harbouring TP53 somatic mutations. J. Pathol. 238, 677-688.

Helgadottir, H., Höiom, V., Tuominen, R., Nielsen, K., Jönsson, G., Olsson, H., and Hansson, J. (2016) Germline CDKN2A mutation status and survival in familial melanoma cases. J. Natl. Cancer Inst. 108, djw135.

Hinshelwood, R. A., Melki, J. R., Huschtscha, L. I., Paul, C., Song, J. Z., Stirzaker, C., Reddel, R. R., and Clark, S. J. (2009) Aberrant de novo methylation of the $p 16^{I N K 4 A} \mathrm{CpG}$ island is initiated post gene silencing in association with chromatin remodelling and mimics nucleosome positioning. Hum. Mol. Genet. 18, 3098-3109.

Hollestelle, A., Nagel, J. H. A., Smid, M., Lam, S., Elstrodt, 
F., Wasielewski, M., Ng, S. S., French, P. J., Peeters, J. K., Rozendaal, M. J., et al. (2010) Distinct gene mutation profiles among luminal-type and basal-type breast cancer cell lines. Breast Cancer Res. Treat. 121, 53-64.

Horcasitas, D. J., Laduca, H., Yussuf, A., Chisholm, G., Chavez, J. R., Fontaine, A. C., and Smith, L. P. (2017) Exploring a possible relationship of germline CDKN2A mutations with breast cancer in a multigene panel cohort. J. Clin. Oncol. 35, e23218.

Jovanovic, J., Rønneberg, J. A., Tost, J., and Kristensen, V. (2010) The epigenetics of breast cancer. Mol. Oncol. 4, 242-254.

Khurana, E., Fu, Y., Chakravarty, D., Demichelis, F., Rubin, M. A., and Gerstein, M. (2016) Role of non-coding sequence variants in cancer. Nat. Rev. Genet. 17, 93-108.

Kim, E. Y., Cho, E. N., Park, H. S., Hong, J. Y., Lim, S., Youn, J. P., Hwang, S. Y., and Chang, Y. S. (2016) Compound EGFR mutation is frequently detected with co-mutations of actionable genes and associated with poor clinical outcome in lung adenocarcinoma. Cancer Biol. Ther. 17, 237-245.

Kitts, A., and Sherry, S. (2011) The single nucleotide polymorphism database (dbSNP) of nucleotide sequence variation. In: The NCBI Handbook. (eds.: McEntyre, J., and Ostell, J.), Chapter 5. US National Center for Biotechnology Information, Bethesda, USA.

Landi, D., Gemignani, F., Barale, R., and Landi, S. (2008) A cata$\log$ of polymorphisms falling in microRNA-binding regions of cancer genes. DNA Cell Biol. 27, 35-43.

Liu, M., Watson, L. T., and Zhang, L. (2015) Predicting the combined effect of multiple genetic variants. Hum. Genomics 9, 18 .

McKenzie, H. A., Fung, C., Becker, T. M., Irvine, M., Mann, G. J., Kefford, R. F., and Rizos, H. (2010) Predicting functional significance of cancer-associated $\mathrm{p} 16^{\mathrm{INK} 4 \mathrm{a}}$ mutations in CDKN2A. Hum. Mutat. 31, 692-701.

Menhas, R., and Umer, S. (2015) Breast cancer among Pakistani women. Iran. J. Public Health 44, 586-587.

Morris, L. G. T., and Chan, T. A. (2015) Therapeutic targeting of tumor suppressor genes. Cancer 121, 1357-1368.

Musgrove, E. A., Liuschkis, R., Cornish, A. L., Lee, C. S. L., Setlur, V., Seshadri, R., and Sutherland, R. L. (1995) Expression of the cyclin-dependent kinase inhibitors $\mathrm{p} 16^{\mathrm{INK} 4}, \mathrm{p} 15^{\mathrm{INK} 4 \mathrm{~B}}$ and p21Waf1/cip1 in human breast cancer. Int. J. Cancer 63, 584-591.

Nagore, E., Montoro, A., García-Casado, Z., Botella-Estrada, R., Insa, A., Lluch, A., López-Guerrero, J. A., and Guillén, C. (2009) Germline mutations in $C D K N 2 A$ are infrequent in female patients with melanoma and breast cancer. Melanoma Res. 19, 211-214.

Nik-Zainal, S., Davies, H., Staaf, J., Ramakrishna, M., Glodzik, D., Zou, X., Martincorena, I., Alexandrov, L. B., Martin, S., Wedge, D. C., et al. (2016) Landscape of somatic mutations in 560 breast cancer whole-genome sequences. Nature 534, 47-54

Oliveira, A. M., Ross, J. S., and Fletcher, J. A. (2005) Tumor suppressor genes in breast cancer: the gatekeepers and the caretakers. Pathol. Patterns Rev. 124, S16-S28.

Phyllodes Tumour Consortium (2008) A comprehensive genetic profile of phyllodes tumours of the breast detects important mutations, intra-tumoral genetic heterogeneity and new genetic changes on recurrence. J. Pathol. 214, 533-544.

Prowse, A. H., Schultz, D. C., Guo, S., Vanderveer, L., Dangel,
J., Bove, B., Cairns, P., Daly, M., and Godwin, A. K. (2003) Identification of a splice acceptor site mutation in $p 16^{I N K 4 \mathrm{~A}}$ $p 14^{A R F}$ within a breast cancer, melanoma, neurofibroma prone kindred. J. Med. Genet. 40, e102.

Puig, S., Potrony, M., Cuellar, F., Puig-Butille, J. A., Carrera, C., Aguilera, P., Nagore, E., Garcia-Casado, Z., Requena, C., Kumar, R., et al. (2016) Characterization of individuals at high risk of developing melanoma in Latin America: bases for genetic counseling in melanoma. Genet. Med. 18, 727-736.

Quesnel, B., Fenaux, P., Philippe, N., Fournier, J., Bonneterre, J., Preudhomme, C., and Peyrat, J. P. (1995) Analysis of p16 gene deletion and point mutation in breast carcinoma. $\mathrm{Br}$ J. Cancer 72, 351-353.

Rayess, H., Wang, M. B., and Srivatsan, E. S. (2012) Cellular senescence and tumor suppressor gene p16. Int. J. Cancer 130, 1715-1725.

Robertson, L. B., Armstrong, G. N., Olver, B. D., Lloyd, A. L., Shete, S., Lau, C., Claus, E. B., Barnholtz-Sloan, J., Lai, R., Il'yasova, D., et al. (2010) Survey of familial glioma and role of germline $p 16^{I N K 4 A} / p 14^{A R F}$ and $p 53$ mutation. Fam. Cancer 9, 413-421.

Rocco, J. W., and Sidransky, D. (2001) p16(MTS-1/CDKN2/ INK4a) in cancer progression. Exp. Cell Res. 264, 42-55.

Royds, J. A., Pilbrow, A. P., Ahn, A., Morrin, H. R., Frampton, C., Russell, I. A., Moravec, C. S., Sweet, W. E., Tang, W. H. W., Currie, M. J., et al. (2016) The rs11515 polymorphism is more frequent and associated with aggressive breast tumors with increased ANRIL and decreased $p 16^{I N K 4 a}$ expression. Front. Oncol. 5, 306.

Shan, M., Zhang, X., Liu, X., Qin, Y., Liu, T., Liu, Y., Wang, J., Zhong, Z., Zhang, Y., Geng, J., et al. (2013) P16 and P53 play distinct roles in different subtypes of breast cancer. PLoS One 8, e76408.

Silva, J., Silva, J. M., Domínguez, G., García, J. M., Cantos, B., Rodríguez, R., Larrondo, F. J., Provencio, M., España, P., and Bonilla, F. (2003) Concomitant expression of $p 16 I N K 4 a$ and $p 14 A R F$ in primary breast cancer and analysis of inactivation mechanisms. J. Pathol. 199, 289-297.

Sonkin, D., Hassan, M., Murphy, D. J., and Tatarinova, T. V. (2013) Tumor suppressors status in cancer cell line Encyclopedia. Mol. Oncol. 7, 791-798.

Spitzwieser, M., Entfellner, E., Werner, B., Pulverer, W., Pfeiler, G., Hacker, S., and Cichna-Markl, M. (2017) Hypermethylation of CDKN2A exon 2 in tumor, tumor-adjacent and tumor-distant tissues from breast cancer patients. BMC Cancer 17, 260.

Tan, W. J., Lai, J. C., Thike, A. A., Lim, J. C. T., Tan, S. Y., Koh, V. C. Y., Lim, T. H., Bay, B. H., Tan, M. H., and Tan, P. H. (2014) Novel genetic aberrations in breast phyllodes tumours: comparison between prognostically distinct groups. Breast Cancer Res. Treat. 145, 635-645.

Turgut, S., Ilhan, M., Turan, S., Karaman, O., Yaylim, I., Kucukhuseyin, O., and Tasan, E. (2017) The role of $p 16$ and MDM2 gene polymorphisms in prolactinoma: MDM2 gene polymorphisms may be associated with tumor shrinkage. In Vivo 31, 357-363.

Xu, L., Sgroi, D., Sterner, C. J., Beauchamp, R. L., Pinney, D. M., Keel, S., Ueki, K., Rutter, J. L., Buckler, A. J., and Louis, D. N. (1994) Mutational analysis of CDKN2 (MTS1/p16 ${ }^{\text {ink4})}$ in human breast carcinomas. Cancer Res. 54, 5262-5264. 